\title{
Paulo Freire, Paul Ricoeur y la identidad narrativa
}

\author{
Manuel Fernando Velasco \\ Departamento de Letras, Comunicaciones y Periodismo \\ UCA, SAN SALVADOR
}

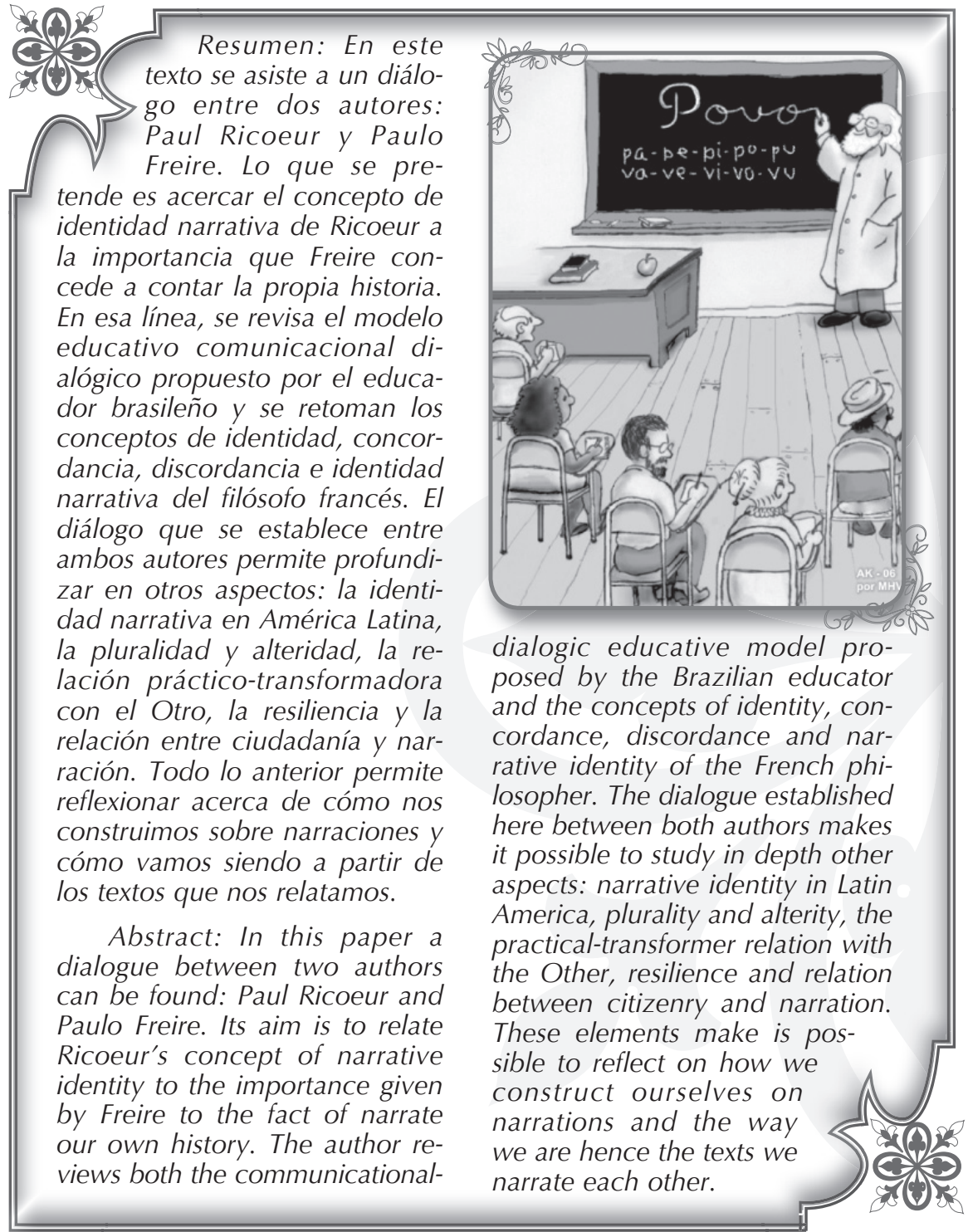




\section{Introducción}

- I curso La construcción de la - identidad en América Latina -impartido por la doctora Andrea Díaz Genis, uruguaya, en octubre del año pasado, como parte del doctorado en Filosofía Iberoamericana de la UCA- dejó en mí varias inquietudes y profundas reflexiones. Hubo una idea que, desde que la leí, me atrajo particularmente:

"La identidad es una construcción que se relata, pero que implica tanto la lectura y relectura del pasado, como la apertura hacia un proyecto. Es más, leemos e interpretamos nuestro pasado de acuerdo con un proyecto. Afirmamos entonces que la identidad forma parte de algo que se cuenta, que se narra, que se 'ensaya'... Es decir, la identidad está mediada por un lenguaje, una manera de 'expresar' con sus reglas, un entramado lingüístico, una determinada manera de expresar las significaciones que implica un aprendizaje cultural" (Díaz Genis, 2004).

Desde ese momento, los planteamientos de Arthur Danto y Paul Ricoeur captaron mi interés. A ninguno de los dos había leído, pero me parecía que debía acercarme al menos al francés Ricoeur (19132005), cuyas ideas acerca de la identidad como ipse y mismo y sus investigaciones acerca de la identidad narrativa resonaron con fuerza en mi interior.

Fue tiempo después, al enfrentarme a la posible estructura del trabajo final, cuando, me parece, encontré el porqué de esa atracción: me pareció que esos conceptos podían acercarse a los de un autor que, aunque no había leído mucho, creía dominar: Paulo Freire (1921-1997). Recordaba vagamente que en alguna parte había leído que para este educador brasileño la alfabetización iba más allá de un mero aprendizaje de lectura y escritura, es decir, las personas debían alfabetizarse para algo más: contar su propia historia, eso era lo realmente valioso, lo que en el fondo importaba. Pero no estaba seguro de si Freire había dicho eso o había formulado algún planteamiento en esa dirección. Tampoco había leído a Ricoeur. Y sin embargo empecé a recorrer ese camino.

Con la idea en la cabeza, releí cuatro libros de Freire y leí varios capítulos de dos libros de Ricoeur. Mi propósito, al iniciar la lectura, era aparentemente sencillo: acercar el concepto de identidad narrativa 
de Ricoeur a la importancia que Freire concede a contar la propia historia, intentando hacer dialogar así a esos dos autores. Lo que presento a continuación es el resultado de esa intención. Sin embargo, más allá de los planteamientos que siguen, gracias a las lecturas redescu- brí a Freire -y de paso me di cuenta de que había entendido menos de la mitad de sus planteamientos- y descrubrí a Ricoeur -con quien disfruté enormemente de su rigurosidad y estructura-, aunque me falta muchísimo por comprender la totalidad de su pensamiento.

\section{EI "método" Freire}

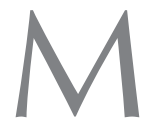

e parece que un primer aspecto que debe tratarse es cómo entendía Freire el proceso de alfabetización. Ello establecerá el punto de partida para acercarnos a la idea de la escritura de la propia historia como parte fundamental del proceso de desarrollo personal de cada ser humano para, bastante más adelante, enlazar esa idea con el concepto de identidad narrativa.

Lo primero que debe decirse al respecto es que Freire no tenía un método para alfabetizar. Como veremos, ese aprendizaje dependía mucho del contexto social y cultural en el que se movieran los educandos y el educador mismo. Sin embargo, sí es posible señalar ciertos elementos que se encuentran a la base de ese proceso que Freire denomina dialógico.

Un primer aspecto que sobresale de inmediato es la ausencia de libro. Para Freire una primera clave radicaba en "simplemente" escuchar, en un diálogo horizontal. ¿Escuchar qué? Precisamente las historias de vida de cada persona, aquello que tenía que contar, algo que sentía la necesidad de relatar. Pero eso requería de un momento previo: vivir en el pueblo al que se iba a alfabetizar. No había límite de tiempo. La idea era instalarse en el lugar y dejarse afectar por los demás. Solo así los alfabetizadores podían darse cuenta de las circunstancias específicas que unían a esas personas. Y solo así, esas personas se sentirían en libertad y propiedad de hablar, de contar situaciones existenciales importantes, afectivamente importantes.

Muchas veces, para motivar la participación, los educadores y las educadoras -quienes ya habían convivido con los pobladoresmostraban láminas o dibujos que reflejaban determinadas situaciones de la vida diaria del lugar que visitaban. A partir de esas representaciones, las personas hablaban de los problemas que se les presentaba y con los que tenían que habérselos para salir adelante.

Así, durante la conversación aparecían ciertas palabras que Freire denominó generadoras porque, 
a través de la combinación de sus elementos básicos, propician la formación de otras. "Como palabras del universo vocabular del alfabetizando, son significaciones constitutivas en sus comportamientos, que configuran situaciones existenciales o se configuran dentro de ellas. Tales significaciones son codificadas plásticamente en cuadros, diapositivas, films, etc., representativos de las respectivas situaciones que, de la experiencia vivida del alfabetizando, pasan al mundo de los objetos. El alfabetizando gana distancia para ver su experiencia, 'ad-mira'. En ese mismo instante, comienza a decodificar" (Freire, 1970).

Entonces, los alfabetizandos parten de algunas pocas palabras que les sirven para generar su universo de vocabulario. Pero antes Cobran conciencia del poder creador de esas palabras: ellas son las que generan su mundo. Las significaciones que establece a partir de esas palabras forma parte de su historia, de lo que les permite constituirse como personas, que hasta ese momento no se consideraban como tales, producto de la marginación, masificación o dominación a la que estaban sometidas (recordemos que el proceso de alfabetización de Freire inicia en una época bien específica: década de los sesenta). "De este modo, al visualizar la palabra escrita, en su ambigua autonomía, ya están conscientes de la dignidad que ella es portadora. La alfabetización no es un juego de palabras, sino la conciencia reflexiva de la cultura, la reconstrucción crítica del mundo humano, la apertura de nuevos caminos, el proyecto histórico de un mundo común, el coraje de decir su palabra" (Freire, 1970).

En otras palabras, partir de su realidad, de lo que ellos viven y asumen como propio, de su realidad inmediata. Intentaré, con un ejemplo de mi cosecha, explicar con más detalle este aspecto. Digamos que, en ese sentido, una palabra generadora, propia de nuestra región, podría ser 'cantarera'. La 'cantarera' no es solo el lugar para llenar con agua los cántaros. Es mucho más que eso: es un lugar de encuentro, un espacio necesario en el vaivén cotidiano, un momento para que las mujeres se re-conozcan y conversen. Así, a partir de esa palabra, que tiene hondo significado en la vida y cultura de las personas que habitan en la ruralidad, los alfabetizadores construían frases u oraciones: La cantarera está ocupada, Hay muchas personas haciendo fila en la cantarera, Iré a la cantarera por agua.

De esta manera, la "lectura" de la palabra generadora posibilita la creación de varias frases, "y solo después de una larga experiencia haciendo frases, teniendo la palabra generadora en diferentes posiciones y funciones, comienza el trabajo de decodificación de la palabra en sílabas y, más tarde, el de la combinación de las sílabas en nuevas palabras y de éstas en nuevas frases" (Freire, 1996). Todo esto considerando, además, "la inseguridad 
del adulto iletrado, que se agravará si se siente tratado como un niño. $Y$ no hay manera más eficaz de respetarlo que acatar su conocimiento de experiencia hecho con el objeto de ir más allá de él (...) Lo que significa para un adulto de treinta, cuarenta años, habituado al peso de su herramienta de trabajo, pasar a manipular el lápiz. Al principio de su experiencia debe haber una desproporción entre la fuerza que se emplea y el peso del lápiz. Y es preciso que se reacondicione poco a poco, con la práctica repetida", aspectos que solo pueden ser tomados en cuenta a partir del conocimiento que arroja la convivencia con aquellos y aquellas que desean alfabetizarse. De allí que "trabajar con los educandos con la idea de crear un ambiente de confianza en el que pueda existir la seguridad es definitivamente favorable al proceso de aprendizaje" (Freire, 1996).

Entonces, para Freire la alfabetización es un acto de conocimiento, de creación, y no de memorización mecánica de letras y sílabas. Los alfabetizados deben ser desafiados a asumir el papel de sujetos del proceso de aprendizaje de la escritura y de la lectura. Y el programa debe surgir de la investigación del propio universo de los alfabetizandos. De allí que para Freire, "el respeto al saber popular implica necesariamente el respeto al contexto cultural. La localidad de los educandos es el punto de partida para el conocimiento que se van creando del mundo. 'Su' mundo, en última instancia, es el primer e inevitable rostro del mundo mismo" (Freire, 1993).

Freire cuenta que no fue fácil llevar a cabo esta forma de alfabetizar. Las personas le decían que sus abuelos, padres y demás conocidos habían aprendido con el abecé en la mano, memorizando letras. Pero él explicaba: “¿Conocen a algún niño que haya aprendido a hablar diciendo $\mathrm{F}, \mathrm{L}$, $M$ ? Me gustaría que pensáramos en lo siguiente: mujeres y hombres cuando son niños no comienzan a hablar con letras sino con palabras que equivalen a frases. Cuando el bebé llora y dice 'mamá', el bebé está queriendo decir: 'Mamá, tengo hambre' o 'mamá, estoy mojado'. Estas palabras con las que los bebés comienzan a hablar se llaman frases monopalábricas, es decir, frases de o con una sola palabra. Pues bien, si así es como todos comenzamos a hablar, ¿cómo es que entonces en el momento de aprender a leer y escribir debemos comenzar a través de la memorización de las letras?" (Freire, 1994).

$Y$ Freire comenta esto porque ello le permitió aprender y crecer en su oficio de educador: "Fue participar en aquellos encuentros, en aquellos debates, lo que por un lado me permitió ir tomando conocimiento de que la práctica social de la que formamos parte va generando un saber propio, y por el otro, de que el 'saber de experiencia de hecho' debe ser respetado. Aún más, su superación pasa por él 
(...) La salida era político-pedagógica. Era el debate, la conversación sincera con que buscaríamos aclarar nuestra posición frente a sus pleitos" (Freire, 1994).

¿Puede, entonces, haber un intento serio de escritura y lectura de la palabra sin la lectura del mundo? Sabemos ya la respuesta. Freire subraya reiteradas veces, a lo largo de sus libros, la importancia de la relación en todo lo que hacemos en nuestra experiencia existencial en cuanto experiencia social e histórica. La importancia de la relación entre las cosas, los objetos entre sí, de las palabras entre ellas en la composición de las frases y de éstas entre sí en la estructura del texto. Esto queda claramente establecido en lo que Freire denomina "programas", manera con la que comúnmente eran Ilamados los contenidos en aquella época. En el II Congreso Nacional de Educación de Adultos, realizado en Río de Janeiro del 6 al 16 de julio de 1958, ya Paulo Freire (1993) subrayaba la importancia de los "contenidos programáticos", que contemplaban lo siguiente:

"Que el programa de dichos cursos, siempre de acuerdo con la realidad local, regional y nacional, sea elaborado con la participación de los educandos, en algunos de sus aspectos, por lo menos los que, flexibles y plásticos, se preocupan:

1. Por aspectos higiénicos, morales, religiosos, recreativos, económicos de la vida local.

2. Por aspectos que engloben la vida regional y nacional, principalmente en lo concerniente al desarrollo del país.

3. Por el desarrollo y la utilización de la dirigencia democrática local

4. Por la creación de nuevas actitudes frente a la familia, a los vecinos, al barrio, al municipio, basadas en espíritu de solidaridad y comprensión".

De este modo, ya desde los años cincuenta, Freire establecía una relación entre la alfabetización, los contenidos por estudiar y el acto político de educar. Respecto a este último punto, el educador brasileño afirmará, muchos años después, cerca de su muerte, las siguientes palabras con las que, a mi parecer, aclara de una buena vez eso de acto político de educar: "No está de más repetir aquí la afirmación, todavía rechazada por mucha gente no obstante su obviedad, la educación es un acto político. Su no neutralidad exige de la educadora que asuma su identidad política y viva coherentemente su opción" (Freire, 1994). 
Entonces, "enseñar a leer las palabras dichas y dictadas es una forma de mistificar las conciencias, despersonalizándolas en la repetición -es la técnica de la propaganda masificadora-" (Freire, 1970). Alfabetizarse es un reconocerse como persona que vive una vida dura, con la que cotidianamente tiene que enfrentarse. Es partir de una realidad, su realidad, porque allí se juega su existencia. Es dotarles a las palabras del significado de la vida cotidiana para verse reflejado en ellas, y con esa imagen re-configurar su propia manera de ser-en-el-mundo. Alfabetizarse no es aprender a repetir palabras, sino aprender a decir su palabra, creadora de cultura. Tal es el "método" de Paulo Freire.

\section{Hacia un modelo educativo comunicacional dialógico}

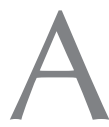

ntes de considerar aspectos del pensamiento de Paul Ricoeur, me parece preciso agregar algunas reflexiones más respecto a la manera de concebir la educación que tenía Freire.

De lo que se ha señalado en el apartado anterior, puede desprenderse la siguiente aseveración: para la persona, aprender a leer es aprender a decir su palabra, entendida como palabra y acción. El pensamiento y la existencia no caminan por separado. Se trata de una palabra viva y dinámica, que dice y transforma el mundo. Así lo plantea Paulo Freire:

"La tendencia, entonces, tanto del educador-educando como de los educandos-educadores es la de establecer una forma auténtica de pensamiento y acción. Pensarse a sí mismos y al mundo, simultáneamente, sin dicotomizar este pensar de la acción. La educación problematizadora se hace, así, un esfuerzo permanente a través del cual los hombres van percibiendo, críticamente, cómo están siendo en el mundo, en el que y con el que están (...) De esta manera, la educación se rehace constantemente en la praxis. Para ser, tiene que estar siendo" (Freire, 1970).

De allí que el modelo educativo comunicacional dialógico se centra en que los interlocutores (personasdocentes-estudiantes-comunidad) piensen y transformen permanentemente su realidad a través del diálogo, la concientización, la reflexiónacción. Esta teoría del diálogo se caracteriza por la colaboración, la unión, la organización y la síntesis de la cultura².

"Nuestro papel no es hablar al pueblo sobre nuestra visión del mundo, o intentar imponerla a él, sino dialogar con él sobre su visión y la nuestra. Tenemos que estar convencidos de que su visión del mundo, manifestadas en las diversas formas de su acción, refleja su situación en el mundo en el que se constituye. La acción educativa y la acción política no pueden prescindir del 
conocimiento crítico de esta situación, so pena de que se transformen en 'bancarias' o en una prédica en el desierto" (Op. cit., pp. 111-112).

En este modelo la idea es que el sujeto dialogue, se concientice, reflexione, actúe, y que esa comunicación-concientización-pensamiento-actuación lo lleve a contribuir en la transformación de la realidad y en la humanización de todos. Todas las personas interesadas buscan la verdad y la raíz de los problemas. Si esto fuera distinto, no se cumpliría lo que dice Paulo Freire: "Si no amo el mundo, si no amo la vida, si no amo a las personas, no me es posible dialogar. Hablar de democracia y callar al pueblo es una farsa. Hablar de humanismo y negar al ser humano es una mentira" (Op. cit.).

Eso es lo que entiende Freire por concientización: que el sujeto se apropie de su realidad, que conozca su circunstancia. Eso no se logra a través de la imposición de determinada realidad. De allí que la educación bancaria es la educación teórica, que se separa de la vida; hay una absolutización de la ignorancia en el educando y una absolutización de la sabiduría del docente.
En síntesis, el modelo dialógico se articula a partir de acciones sociales, culturales, morales, políticas, éticas. Su accionar va en busca de una mayor justicia social, hecho que incluye clarificaciones en torno a la libertad responsable, la equidad y la calidad de vida. En este modelo, el conocimiento se manifiesta en el saber hacer, la reflexión en el saber explicar lo que se hace y la acción-reflexión en las verbalizaciones de los conocimientos que se generan a partir de la conjunción entre el conocimiento como tal y el conocimiento recreado o reconstruido por todas las personas involucradas y comprometidas en la transformación de su realidad individual y colectiva.

En el modelo dialógico, la enseñanza-aprendizaje vincula la discusión crítica a la búsqueda de los porqués, al planteamiento de hipótesis, a la interpretación de significados, a la redefinición de situaciones, a la reconfiguración de conceptos, todo lo cual conducirá a una verdadera liberación, al nacimiento de un hombre nuevo, un ser más, en palabras de Freire.

\section{Relato e identidad, historia y narratividad: Ricoeur}

os estudios del filósofo y antropólogo Paul Ricoeur abarcan aspectos de existencialismo, psicoanálisis, filosofía del lenguaje, hermenéutica, filosofía analítica, semiótica, lingüística y estructuralismo. Sin embargo, para los objetivos de este trabajo $-\mathrm{y}$ con los elementos de la pedagogía de Freire como eje-, me centraré en los planteamientos que este autor francés elabora respecto de la identidad narrativa y personal. Específicamente, sigo acá los estudios quinto y sexto 
del Sí mismo como otro (1996) y los textos "Para una teoría del discurso narrativo" —núcleo inicial de lo que sería posteriormente Tiempo y narración- y "La identidad narrativa" -conferencia pronunciada en 1986-, ambos recopilados en el libro Historia y narratividad (1999) ${ }^{3}$.

Un eje fundamental en el pensamiento de Ricoeur lo representa la problemática del actuar humano. En su conjunto, la filosofía de Ricoeur podría caracterizarse como una filosofía de la acción: en un primer momento, le interesa la estructura del actuar humano en relación con la temática de la voluntad; después, estudia las estructuras inconscientes del deseo; finalmente, muestra las relaciones entre tiempo y narración. De hecho, para varios autores es en Sí mismo como otro en donde la filosofía de la acción toma forma. El objetivo de esta obra es elaborar una comprensión del ser humano (que Ricoeur llama hermenéutica de sí mismo), según tres dimensiones básicas: lingüística, narrativa y ética. Así, este libro lo componen diez estudios, que van -como el mismo Ricoeur explica en el prólogo- desde una filosofía del lenguaje (estudios primero y segundo), una filosofía de la acción (estudios tercero y cuarto), una confrontación entre filosofía analítica y hermenéutica que plantea el problema de la identidad personal (estudios quinto y sexto), hasta aspectos éticos y morales (estudios octavo y noveno), el cuestionamiento del actuar humano y una reflexión de los términos "ser" y "alteridad" (estudio décimo).

Respecto a los estudios quinto y sexto -que son los que consideraré para este trabajo-, el filósofo y antropólogo francés señala que "la cuestión de la identidad, ligada a la de la temporalidad, se reanudará en el punto en el que la había dejado en Temps et récit III, con el título de 'identidad narrativa', pero con nuevos recursos proporcionados por el análisis de la identidad personal en función de criterios de identificación. Lo que acabamos de llamar competencia entre dos tradiciones filosóficas ${ }^{4}$, será sometido al arbitraje de la dialéctica entre la identidad-idem y la identidad-ipse, de la cual hemos hecho, con el carácter reflexivo del sí, el segundo rasgo gramatical del sí mismo" (Ricoeur, 1996).

Así, los estudios quinto y sexto muestran que solo saliendo de los límites impuestos por la filosofía analítica es posible comprender en su unidad las diversas acciones de un agente. Para ser inteligible, la acción ha de ser narrada, lo que lo Ilevará, más adelante (siguientes estudios), a colocar la narración como eje entre la teoría de la acción y la teoría moral.

En "La identidad narrativa" -que, como señalé, es una conferencia que dicta en 1986-, Ricoeur explica de dónde viene su reflexión y para dónde partirá.

Ricoeur asegura que retoma el punto en donde se quedó en las 
últimas páginas de Tiempo y narración III: el problema de la identidad narrativa, "es decir, de aquella identidad que el sujeto humano alcanza mediante la función narrativa (...) Conocerse, decía entonces, consiste en interpretarse a uno mismo a partir del régimen del relato histórico y del relato de ficción" (Ricoeur, 1999).

Luego añade que, a partir de allí, iniciará un nuevo recorrido en el que "partiré de la problemática de la identidad considerada desde la noción de 'sí mismo'. Nos encontramos con un problema en la medida en que 'idéntico' tiene dos sentidos, que corresponden respectivamente a los términos latinos idem e ipse. Según el primer sentido (idem), 'idéntico' quiere decir sumamente parecido y, por tanto, inmutable, que no cambia a lo largo del tiempo. Según el segundo sentido (ipse), 'idéntico' quiere decir 'propio' y su opuesto no es 'diferente' sino otro, extraño. Este segundo concepto de 'identidad' guarda una relación con la permanencia en el tiempo que sigue resultando problemática. Mi tema de estudio es la propia identidad como ipseidad, sin juzgar de antemano el carácter inmutable o cambiante del sí mismo" (Ricoeur, 1999).

Como bien hace notar Díaz Genis (2004), la ventaja de la identidad como ipse es que "si se permanece en el círculo de la identidad-mismidad, la alteridad de cualquier otro distinto de sí no ofrece nada original, solo se entien- de como antónimo de la mismidad, figura de paso. Otra cosa sucede si se empareja la alteridad con la ipseidad. El sí mismo como otro sugiere que la ipseidad de sí mismo implica una alteridad en un grado tan íntimo que no se puede pensar una sin la otra".

La identidad concebida como 'lo mismo' (idem) se sustituye por una identidad concebida como 'sí mismo' (ipse). La primera es una identidad que no admite cambios, es estática; mientras que la ipseidad incluye el cambio. Es en este aspecto donde se relaciona el relato: "El relato es la dimensión lingüística que proporcionamos a la dimensión temporal de la vida. Aunque es complicado hablar directamente de la historia de una vida, podemos hablar de ella indirectamente gracias a la poética del relato. La historia de la vida se convierte, de ese modo, en una historia contada" (Ricoeur, 1999).

Así, la persona tiene una historia, su propia historia, "un sujeto capaz de designarse a sí mismo al significar el mundo. Esto nos remite a la cuestión de la identidad personal, que solo puede articularse en la dimensión temporal de la existencia humana (...) La comprensión de sí es una interpretación, la interpretación de sí a su vez se encuentra en la narración, y esta última se vale tanto de la historia como de la ficción, haciendo de la historia de una vida una historia de ficción o si se prefiere una ficción histórica" (Díaz Genis, 2004). 
De allí que podamos afirmar que nos construimos sobre narraciones, somos a partir de los relatos. Ello es lo que asegura nuestra identidad a lo largo de lo cambiante de nuestras vidas. Como personajes de un relato, nuestra identidad es dinámica: "El relato construye la identidad del personaje, que podemos llamar su identidad narrativa, al construir la identidad dinámica propia de la historia contada. La identidad de la historia forja la del personaje" (Ricoeur, 1999). Por eso, "la literatura, las lecturas narrativas con las que nos hemos familiariza- do, nos ayudan a construir nuestra propia identidad narrativa" (Díaz Genis, 2004).

Para finalizar este apartado, cito de nuevo a Ricoeur (1996), esta vez con la teoría de Freire que se ha visto antes en primer plano: "De esta discusión se deduce que relatos literarios e historias de vida, lejos de excluirse, se complementan, pese a, o gracias a, su contraste. Esta dialéctica nos recuerda que el relato forma parte de la vida antes de exiliarse de la vida en la escritura; vuelve a la vida según los múltiples caminos de la apropiación".

\section{Concordancia, discordancia y peripecia en Ricoeur; situaciones límite, actos límite e inédito viable en Freire}

A ntes de reflexionar respecto a qué resulta de todo esto — de este diálogo entre Ricoeur y Freire- (aunque algunos puntos de encuentro resaltan desde ya con suficiente evidencia), quiero detenerme en algunos conceptos de ambos autores que, me parece, terminan por acercarlos aún más.

Para Ricoeur (1999), una historia (story) describe una serie de acciones y de experiencias llevadas a cabo por algunos personajes reales o imaginarios. Esos personajes aparecen representados en situaciones que cambian; más aún, los personajes reaccionan cuando se modifican las situaciones. A su vez, "esos cambios ponen de relieve aspectos ocultos de la situación y de los personajes, y dan lugar a una prueba o a un desafío (predicament) que reclama un pensamiento, una acción o ambos. La respuesta que se dé a dicha prueba supondrá la conclusión de la historia". Y de hecho, "el paso decisivo a una identidad narrativa personal se da cuando se pasa de la acción al personaje y se dice que es el personaje el que hace la acción en el relato. Desde esta perspectiva, narrar es decir quién ha hecho qué, por qué y cómo, desplegando en el tiempo la conexión de puntos de vista" (Díaz Genis, 2004).

Ahora bien, la acción que cuenta el relato, y que es llevada por el personaje, posee concordancia: el principio de orden que rige la manera en que se disponen o distribuyen los hechos, desde un 
comienzo, un medio, hasta un fin. Se trata de una serie de acontecimientos encadenados, apropiadamente distribuidos a lo largo del relato, regidos bajo el principio de la verosimilitud.

No obstante lo anterior, en el relato también aparecen discordancias: giros o cambios en la fortuna o aspectos de la vida del personaje, "que hacen de la trama una transformación regulada, desde una situación inicial hasta otra terminal. Aplico el término de configuración a este arte de la composición que media entre concordancia y discordancia" (Ricoeur, 1996). Con esto último, Ricoeur hace referencia a la peripecia: la propiedad de un acontecimiento de poder haber sido otro o incluso de no haber sido en modo alguno. Eso hace que, precisamente, la acción cobre un sentido más profundo, ya que no se trata de un relato lineal, en el que todo lo que sucede es esperado, tristemente previsible, o, peor aún, no pasa nada. En el relato, los personajes no carecen de discordancias, es decir, no llevan una vida de continuum concordante. Más bien es todo lo contrario: aparecen acontecimientos inesperados -que en lo personal denomino puntos de quiebre-, que le dotan al relato de un acontecimiento imprevisto que viene a quebrar o romper con la linealidad monótona del relato predecible. Justamente son esos puntos de quiebre los que captan la atención y terminan por atrapar el interés del lector, quien se identifica, se reconoce, se re-crea, en el o los hechos que han venido a alterar la "quietud" del personaje.

Ahora bien, lo anterior reviste importancia porque "si toda historia, en efecto, puede considerarse como una cadena de transformaciones que nos lleva de una situación inicial a una situación final, la identidad narrativa del personaje sólo puede ser el estilo unitario de las transformaciones subjetivas reguladas por las transformaciones objetivas (...) Resulta que la identidad narrativa del personaje sólo puede ser correlativa de la concordancia discordante de la propia historia" (Ricoeur, 1999).

El lector se identifica con el personaje y vive con él sus peripecias; toma partido, "opina", quiere saber qué sucederá, "evalúa" las decisiones que toma, "participa" de la acción, y "su fortuna o su desgracia nos parecen merecidas o inmerecidas. Incluso en la novela moderna, en la que la calificación moral de los personajes es tremendamente ambigua, no podemos dejar de querer el bien de aquellos que estimamos. Resulta comprensible por qué sucede de ese modo: la intelección narrativa se asemeja al juicio moral, en la medida en que explora los caminos mediante los que la virtud y el vicio conducen o no a la felicidad y a la desgracia" (Ricoeur, 1999).

A partir de acá, se plantea un aspecto de enorme importancia: el de la apropiación que lleva a cabo 
el sujeto real —el lector, en este caso- de los significados vinculados al héroe ficticio de una acción en sí misma ficticia. "¿Qué refiguración del sí mismo surge de esta apropiación mediante la lectura?", se pregunta Ricoeur (1999).

Por su parte, Freire plantea que los hombres y las mujeres se encuentran en su vida social y personal con obstáculos que es preciso vencer. A esas barreras las llama situaciones límite. Frente a esas situaciones límite, las personas pueden reaccionar de manera diversa: pueden percibirlas como insuperables o como algo que saben que existe y que es preciso romper, y entonces se empeñan en su superación. ¿Cómo pueden las personas vencer esas situaciones límite y sobrepasarlas?

"Al separarse del mundo que objetivan, al separar su actividad de sí mismos, al tener el punto de decisión de su actividad en sí y en sus relaciones con el mundo y con los otros, los hombres sobrepasan las 'situaciones límite', que no deben ser tomadas como si fueran barreras insuperables, más allá de las cuales nada existiera (...) Se revelan así como lo que realmente son: dimensiones concretas e históricas de una realidad determinada, dimensiones desafiantes" (Freire, 1970).

Ahora bien, a las acciones necesarias para romper las situaciones límite, Freire las llama actos límite, "aquellos que se dirigen a la superación y negación de lo otorgado, en lugar de implicar su aceptación dócil y pasiva. Esta es la razón por la cual no son las situaciones límite, en sí mismas, generadoras de un clima de desesperanza, sino la percepción que los hombres tengan de ellas en un momento histórico determinado, como un freno para ellos, como algo que ellos no pueden superar. En el momento en que se instaura la percepción crítica en la acción misma, se desarrolla un clima de esperanza y confianza que conduce a los hombres a empeñarse en la superación de las situaciones límite. Dicha superación, que no existe fuera de las relaciones hombre-mundo, solamente puede verificarse a través de la acción de los hombres sobre la realidad concreta en que se dan las situaciones límite" (1970).

Así, para los dominadores las situaciones límite serán determinantes históricos frente a las cuales no hay nada que hacer más que adaptarse. En cambio los oprimidos, cuando perciben claramente que los temas que desafían a la sociedad no están cubiertos por las situaciones límite, se sienten en el deber de romper esa barrera y traspasar la frontera entre el ser y el ser más. Se trata de una creencia en un sueño posible de liberación a través de la concientización, que da inicio desde la alfabetización. La creencia en la utopía que vendrá, si los que escriben su historia así lo quieren. A esa categoría Freire le llama inédito viable: algo que en el sueño utópico se sabe que existe, pero que solo 
se conseguirá a través de la praxis liberadora que pasa por la acción dialógica. El educador brasileño lo plantea de la manera siguiente:

"Lo inédito viable es en realidad una cosa inédita, todavía no conocida y vivida claramente pero ya soñada, y cuando se torna en 'percibido destacado' por los que piensan utópicamente, entonces estos saben que el problema ya no es un sueño y que puede hacerse realidad. Así, cuando los seres conscientes quieren, reflexionan y actúan para derribar las situaciones límite que los/las obligan como a casi to- dos y todas a ser menos, lo inédito viable ya no es él mismo, sino su concreción en lo que antes tenía de no viable" (Freire, 1993).

De este modo, Paulo Freire va entendiendo la relación pedagógica entre los hombres y las mujeres del mundo, a quienes les abre la posibilidad de liberarse cuando tomen sus historias como tema de reflexión y puedan de esta forma enfrentar sus problemas. Así, lo que antes no parecía viable, se va transformando en inédito viable. De allí que el educador plantee con firmeza lo siguiente (1993):

"Una de las tareas, a través del análisis político serio y correcto, es descubrir las posibilidades - cualesquiera que sean los obstáculos - para la esperanza (...) No entiendo la existencia humana y la necesaria lucha por mejorarla sin la esperanza y sin el sueño (...) Esto no quiere decir, sin embargo, que porque soy esperanzado atribuya a mi esperanza el poder de transformar la realidad, y convencido de eso me lance al embate sin tomar en consideración los datos concretos, materiales, afirmando que con mi esperanza basta (...) Pensar que la esperanza sola transforma el mundo y actuar movido por esa ingenuidad es un modo excelente de caer en la desesperanza. Prescindir de la esperanza que se funda no sólo en la verdad sino en la calidad ética de la lucha es negarle uno de sus soportes fundamentales. En cuanto necesidad ontológica, la esperanza necesita de la práctica para volverse historia concreta (...) En las situaciones límite, más allá de las cuales se encuentra lo inédito viable, a veces perceptible, a veces no, se encuentran razones de ser para ambas posiciones: la esperanzada y la desesperanzada".

En ese orden de ideas, Ricoeur, en el séptimo estudio del libro Sí mismo como otro (denominado "El sí y la intencionalidad ética"), 
plantea establecer la primacía de la ética sobre la moral, es decir, de la intencionalidad sobre la norma. Es decir, a las dimensiones lingüística, práctica y narrativa de la ipseidad (que desarrolla en los estudios anteriores), le agrega una nueva, a la vez ética y moral. ¿Y a qué llama Ricoeur intencionalidad ética? "A la intencionalidad de la 'vida buena' con y para otro en instituciones justas".

El autor va explicando cada componente de esa definición, algo que no retomaremos acá, pues escapa a los objetivos de este trabajo. Sin embargo, es importante tomar en cuenta lo siguiente: "La ventaja principal de una irrupción en la problemática ética por la noción de 'vida buena' es la de no hacer referencia directamente a la ipseidad bajo la figura de la estima de sí. Y, si la estima de sí extrae efectivamente su primera significación del movimiento reflexivo por el que la valoración de ciertas acciones estimadas buenas se vuelve hacia el autor de estas acciones, esta signifi- cación sigue siendo abstracta mientras le falte la estructura dialógica introducida por la referencia al otro. A su vez, esta estructura dialógica sigue estando incompleta fuera de la referencia a instituciones justas. En este sentido, la estima de sí sólo tiene pleno sentido al término del recorrido de sentido jalonado por los tres componentes del objetivo ético" (Ricoeur, 1996).

Más aún, la unidad narrativa "no designa el último grado en la escala de la praxis. En una perspectiva deliberadamente ética, la idea de una concentración de la vida en forma de relato está destinada a servir de punto de apoyo al objetivo de la vida buena".

Todo parece indicar que Ricoeur y Freire nunca se conocieron. Ninguno de los dos cita al otro. $Y$ sin embargo, sus propuestas $y$ planteamientos — distancias obvias de por medio- corren paralelos y establecen contactos. A veces, sus itinerarios tienden a coincidir. Intentemos profundizar en qué sucede cuando eso ocurre.

\section{6. ¿Qué resulta de todo esto? Identidad latinoamericana y más}

"En uno de los primeros momentos de nuestra lucha tuvimos que cortar las cercas del alambre de púas del latifundio con la fuerza que recibimos de nuestra unión. Cortamos y entramos. Pero cuando llegamos adentro descubrimos que en nosotros mismos había otras cercas más difíciles que cortar. La del analfabetismo, la de la ignorancia, la del fatalismo. Nuestra ignorancia es la alegría de los latifundistas, así como la lectura, la mejora de nuestra memoria y el progreso de nuestra cultura 
los hace temblar de miedo. Por eso tenemos que transformar lo que ayer fue un latifundio en un gran centro de cultura".

(Joven líder campesino del sur de Brasil. Tomado de Cartas a Cristina. Reflexiones sobre mi vida y trabajo, de Paulo Freire)

El ejercicio de lectura que he llevado a cabo con estos dos autores ha sido altamente gratificante $y$, me parece, existen suficientes elementos como para establecer distintas reflexiones que vayan en diversas direcciones. Enumero a continuación las que considero más apropiadas para los objetivos de este trabajo.

\subsection{La identidad narrativa en Amé- rica Latina}

Ha quedado demostrado que, ciertamente, el proceso alfabetizador de Paulo Freire no persigue la simple adquisición de las habilidades requeridas para que la persona pueda leer y escribir. El proceso, en todo caso, no acaba allí. No es esa la intención de fondo, sino ésta: que después de aprender la lectura y la escritura, cada persona escribarelate-narre su propia historia. Se trata de re-configurar su propia manera de ser-en-el-mundo, aprender a decir su palabra para ser-más.

¿Y qué es lo que nos permite definirnos como latinoamericanos a pesar de las múltiples diferencias que existen entre nosotros, tanto entre países como al interior de cada país, en cada barrio, departamento, zona o región? Precisamente, "/o que nos permite decir que tenemos algo en común, a pesar de las diferencias, es una determinada narración de nosotros mismos. Esto es lo que nos permite decir que algo permanece igual a sí mismo, no es la mismidad lo que lo permite, sino la capacidad que tenemos los seres humanos de designarnos a nosotros mismos, de sentir, participar y narrar una misma pertenencia, que no solo se relaciona con un pasado, sino también con un proyecto" (Díaz Genis, 2004).

Los planteamientos de Freire y Ricoeur son, en ese orden de ideas, de importancia a la hora de construir las identidades de América Latina. Podemos responder la pregunta de quiénes somos los latinoamericanos, "a través de una construcción, comprensión, interpretación que hemos hecho de nosotros mismos y que nos relatamos" (Díaz Genis, 2004).

Esto dice el educador brasileño: "Tal vez sea ése el sentido más exacto de la alfabetización: aprender a escribir su vida, como autor y como testigo de su historia; biografiarse, existenciarse, historizarse" (Freire, 1970).

Y esto dice el antropólogo francés: "La mediación narrativa subraya que una de las características 
del conocimiento de uno mismo consiste en ser una interpretación de sí" (Ricoeur, 1999). Y ya antes hemos citado las siguientes palabras: "Aunque es complicado hablar directamente de la historia de una vida, podemos hablar de ella indirectamente gracias a la poética del relato. La historia de la vida se convierte, de ese modo, en una historia contada". Y "relatos literarios e historias de vida, lejos de excluirse, se complementan, pese a, o gracias a, su contraste" (Ricoeur, 1996).

Así pues, la lectura y la escritura hacen adquirir una identidad hecha y rehecha a través de los relatos. Pero -y es esta una modesta contribución personal a la discusión que acá se desarrolla- no solo de los relatos leídos, sino también a través de los propios, de los relatos que personalmente voy elaborando, sean estos orales o escritos. Cotidianamente construimos relatos orales en las conversaciones con los demás, y también construimos relatos a través de pequeños poemas, cuentos, redacciones, fragmentos mínimos en donde lo importante no es la puntuación y la ortografía sino el contenido, por muy sencillo que sea el relato o por muy humilde que sea el vocabulario y la persona misma que lo escribe.

Entonces, cómo yo me narro, cómo me relato, cómo me nombro, cómo me construyo, cómo me designo a través de palabras; también, qué cuento de mí, que relatos no se quedan dentro de sí sino que se dan a conocer: todo ello nos define, primero como personas $y$, después, como latinoamericanos. Tal es la identidad narrativa de Ricoeur. Tal es el sentido del proceso alfabetizador de Freire.

Contamos y escribimos historias no solo para pasar el tiempo. Hay una necesidad, individual y colectiva en ello. Así, las culturas adquieren, crean y recrean su identidad narrando historias y narrándose historias. El arte de narrar y leer proporciona unidad a la vida e identidad.

En otras palabras: nos comprendemos mejor, individual y colectivamente, a través de los textos que leemos y escribimos, en los que nos descubrimos y reinventamos nuestro ser. Retomando a Díaz Genis y a Nicol, somos siendo.

\subsection{El otro: yo como tú. Identidad plural, la alteridad}

Ricoeur (1996) es claro al plantear que en la noción de "vida buena" no hay una referencia directa a la ipseidad bajo la figura de la estima de sí. Es más, la significación de ciertas acciones estimadas como buenas, que repercuten favorablemente en el autor de esas acciones, "sigue siendo abstracta mientras le falte la estructura dialógica introducida por la referencia al otro". De igual manera, el modelo dialógico de Freire busca que el sujeto dialogue con otro, se concientice, reflexione y actúe, y que esa comunicación-concientizaciónpensamiento-actuación lo lleve a contribuir en la transformación de la realidad y en la humanización de todos. 
En esa línea, leamos atentamente las siguientes palabras de Freire: "Es en la práctica de experimentar las diferencias donde nos descubrimos como yos y como tús. En rigor, siempre es el otro, en cuanto tú, el que me constituye como yo en la medida en que yo, como tú de otro, lo constituyo como yo" (Freire, 1994). Y Ricoeur: "No puedo estimarme a mí mismo sin estimar al otro como a mí mismo. 'Como a mí mismo' significa: tú también eres capaz de comenzar algo en el mundo, de actuar por razones, de jerarquizar tus preferencias, de estimar los fines de tu acción y, de este modo, estimarte a ti mismo como yo me estimo a mi mismo... De este modo se vuelven equivalentes la estima del otro como sí mismo y la estima de sí mismo como otro... El otro es tanto el otro como el tú" (Ricoeur, 1996).

No somos, pues, unicidad, sino pluralidad. No soy un yo que se encierra en sí mismo (ensimismamiento), sino un yo abierto al otro, un tú que me constituye, un tú al que debo estimar de la misma manera en que me estimo a mí mismo. Comprender esto es también comprender que igualmente "somos una pluralidad de culturas, etnias, modos de vida, discursos, sensibilidades. La colonización de América, el etnocentrismo, racismo, el poder de las culturas hegemónicas, nos ha impedido la posibilidad de legitimar múltiples relatos, modos de vida, etc." (...) La ipseidad sería no solo la alteridad de una vida que se mueve, "sino también de una mismidad que puede reconocerse en los otros, porque es también los otros, porque en definitiva acepta la pluralidad que somos" (Díaz Genis, 2004).

Lo anterior pasa además por desterrar de nuestros relatos -leídos y escritos, escuchados y contados - la insustancial idea de que lo diferente a nosotros es inferior. No podemos seguir negando alteridades, pues convivimos diariamente con la diversidad. Para Freire, esa tendencia que nos lleva a afirmar que lo diferente de nosotros es inferior parte de la idea "de que nuestra forma de estar siendo no solo es buena sino que es mejor que la de los otros, diferentes de nosotros. Esto es la intolerancia. Es el gusto irresistible de oponerse a las diferencias" (Freire, 1994).

El negro, el indígena, la mujer, el campesino, mi vecino, los habitantes de determinada zona geográfica del país, los que habitan otras culturas, en fin, el Otro, tiene derecho a ser mi contrario, tiene derecho a pensar distinto, a sentir diferente, a ser Otro. Y eso no lo convierte en mi enemigo ni en mi contrario. Tanto derecho tiene a disentir como yo de hacerlo cuando así lo estime conveniente.

Ahora bien, tampoco se trata de abogar por un consenso ingenuo en el que pretendamos estar todos y todas absolutamente de acuerdo para convivir "armoniosamente y en paz". En esta línea me parecen muy 
interesantes los planteamientos de

la francesa Chantal Mouffe (2003):

"La novedad de la política democrática no es la superación de esta oposición nosotros/ellos - que es una imposibilidadsino la diferente forma en que ésta se plantea. La cuestión crucial estriba en establecer esta discriminación entre el nosotros y el ellos de un modo que sea compatible con la democracia pluralista (...) Considerado desde el punto de vista del 'pluralismo agonístico', el objetivo de la política democrática es construir de tal forma el 'ellos' que deje de ser percibido como un enemigo a destruir y se conciba como un 'adversario', es decir, como alguien cuyas ideas combatimos pero cuyo derecho a defender dichas ideas no ponemos en duda".

\subsection{Intenciones éticas. Praxis}

$Y$ sin embargo, siguiendo el orden de ideas que se traen desde el apartado anterior, ¿cómo hacer con la internalización que en nuestro relato acerca de nosotros mismos hemos hecho del colonizador, del amo, del dueño, del capataz, del superior, de quien está por encima de los demás? ¿Cómo hacer para, desde las pequeñas cuotas de poder que vamos alcanzando, no repetir patrones de conducta y romper con la "lógica" de que si fui víctima ahora puedo victimizar, si estuve sojuzgado por el opresor ahora puedo revertir el papel y mantener el sometimiento de los oprimidos? No podemos olvidar en este sentido el poder que "produce", como decía
Foucault, "cuerpos, sujetos, pero también relatos y maneras de contarnos a nosotros mismos. Modos de narrarnos predominantes y también 'panópticos' internalizados, que están presentes a la hora de contestarnos no solo quiénes somos, sino también qué clase de ser humano o idea de hombre-mujer realizamos o llevamos a cabo" (Díaz Genis, 2004). ¿Es posible, pues, romper con ese ciclo?

Para Freire (1970), es posible, aunque se trate de un "parto doloroso". Desde su punto de vista, el esfuerzo debe concretarse desde un modelo dialógico liberador e insiste en que los oprimidos - los negados, los excluidos, los marginados- deben construir su liberación y a la vez descubrir que alojan al opresor:

"Casi siempre, en un primer momento de este descubrimiento, los oprimidos, en vez de buscar la liberación (...) 
tienden también a ser opresores o subopresores. La estructura de su pensamiento se encuentra condicionada por la contradicción vivida en la situación concreta, existencial, en que se formaron (...) Por esto, la liberación es un parto. Es un parto doloroso. Nace de él un hombre nuevo, que solo es viable en la superación de la contradicción opresoresoprimidos que, en última instancia, es la liberación de todos. La superación de la contradicción es el parto que trae al mundo a un hombre que se libera - ni opresor ni oprimido-, que es el hombre nuevo (...) Esta liberación no se puede dar, sin embargo, en términos meramente idealistas. Se hace indispensable que los oprimidos, en su lucha por la liberación, no conciban la realidad concreta de la opresión como una especie de mundo cerrado (en el cual se genera su miedo a la libertad) del cual no pueden salir, sino como una situación que solo los limita y que ellos pueden transformar. Es fundamental entonces que, al reconocer el límite que la realidad opresora les impone, conviertan este reconocimiento en el motor de su acción liberadora".

Para Freire, pues, la pedagogía del oprimido debe ser elaborada con el oprimido y no para el oprimido. Sitúa la construcción del conocimiento al interior de la "praxis". Por tanto, como la relación con el Otro no es solamente teórica, sino también práctico-transformadora, tenemos como resultado el que no solo se transforman las opiniones de los sujetos respecto del Otro, sino que también ese Otro cambia.

En esa línea, Ricoeur (1996) denomina al último grado de la praxis "la unidad narrativa de una vida", término en el que no se subraya tanto "la función de reunión, ejercida por el relato en la cima de la escala de la praxis, como la unión que el relato realiza entre las estimaciones aplicadas a las acciones y la evaluación de los personajes mismos. La idea de unidad narrativa de una vida nos garantiza así que el sujeto de la ética no es otro que aquel a quien el relato asigna una identidad narrativa".

Ricoeur coloca así la narración como eje entre la teoría de la acción y la teoría moral, en donde la primacía la tiene la intencionalidad ética: la intencionalidad de la vida buena con y para otro en instituciones justas, y solo en el recorrido de los tres componentes de esa intencionalidad - vida buena, con y para otro, en instituciones justas- la estima de sí adquiere pleno sentido.

La relación entre los planteamientos de ambos autores entusiasma. La cita de Freire que sigue a continuación (1970) termina por 
apuntalar, me parece, este aspecto: "La existencia, en tanto humana, no puede ser muda, silenciosa, ni tampoco nutrirse de falsas palabras, sino de palabras verdaderas con las cuales los hombres transforman el mundo (...) Precisamente por esto, nadie puede decir la palabra verdadera solo (...) Decir la palabra, referida al mundo que se ha de transformar, implica un encuentro de los hombres para esta transformación".

\subsection{Asumir mis discordancias. El inédito viable}

Recordemos que la consecución de la concientización y liberación querida por Freire para por romper con las situaciones límite (barreras u obstáculos que es preciso vencer) mediante los actos límite (esfuerzos que buscan superar lo otorgado, en lugar de una aceptación dócil y pasiva) para alcanzar, así, el inédito viable (la utopía que vendrá, que se sabe que existe y que se consigue sólo a través de la praxis liberadora que pasa por la acción dialógica).

También recordemos que para Ricoeur en el relato aparecen concordancias (orden en la disposición y distribución de hechos) y también discordancias (cambios en aspectos de la vida del personaje), lo que da paso a la configuración (la composición que media entre concordancia y discordancia) y a la peripecia (posibilidad de un acontecimiento de haber sido otro o de no haber sido). A partir de acá, el sujeto real -el lector, en este caso- lleva a cabo una apropiación de los significados vinculados al héroe ficticio de una acción asimismo ficticia. En esa apropiación o refiguración, "el sí mismo no se conoce de un modo inmediato, sino indirectamente, mediante el rodeo de toda clase de signos culturales, que nos llevan a defender que la acción se encuentra simbólicamente mediatizada. La mediación narrativa subraya, de ese modo, que una de las características del conocimiento de uno mismo consiste en ser una interpretación de sí (...) Por otro lado, la recepción del relato que lleva a cabo el lector da lugar, precisamente, a toda una variedad de modalidades de identificación" (Ricoeur, 1999).

Intentaré hacer un paralelismo conceptual de ambas posturas. Imaginemos una persona cuya vida transcurre "en concordancia", en aparente normalidad hasta que, de pronto, le sucede algo que rompe la "linealidad" de su accionar cotidiano. Se trata de una "discordancia" en su vida, una irrupción que viene a quebrar o romper su rutina de vida. Con el tiempo, esa "discordancia" crece, se sale de sus manos y se vuelve un obstáculo, una barrera, una "situación límite" a la que debe encarar y superar para que su vida sea "buena", digna. La situación que vivirá una vez supere ese escollo apenas y puede imaginarla, aún es inédita, pero considera viable su logro, se "identifica" con la escena que imagina y espera su consecución. Así, lleva a cabo diversas acciones límites que, cier- 
tamente, le permiten romper con esa situación límite, con lo que su vida vuelve a la "normalidad", sintiéndose "en concordancia" consigo misma. Sin embargo, dos semanas después, aparece de nueva una situación "discordante", y vuelve a empezar el ciclo.

Apliquemos eso a la vida de la persona que lee. Su identidad narrativa se ve fortalecida al leer relatos en los que, al igual que sucede en su cotidianidad, aparecen puntos de quiebre que requieren de un acción del personaje. ¿Qué hará ahora? ¿Cómo solventará ese giro inesperado en su vida? ¿De qué manera sus decisiones afectarán la trama de la historia y la vida de otros personajes? ¿Qué consecuencias se derivarán? Todas son preguntas que la persona que lee se hace también cuando en su vida aparecen situaciones límite que requieren ser superadas. De esta manera, entonces, se identifica plenamente con el relato y su identidad se va construyendo, "configurando".

Apliquémoslo ahora a la vida de la persona que escribe. Se siente dichosa de poder decir su propia palabra. No importa que no sea un cuento, mucho menos una novela, sino apenas dos o tres párrafos en los que relata cómo se siente, qué le está afectando, cómo va haciendo para superar problemas y salir adelante, quiénes la colman de afecto y la animan a salir adelante. Relata su historia de vida y de esa manera construye y descubre su identidad. El texto es todavía un in- édito viable, pero ya lo visualiza, e intentará superar todos los obstáculos posibles para escribir su palabra y transformarse por dentro.

Definitivamente, qué importancia tiene la alfabetización en la vida de las personas. No se trata solo de aprender a leer y escribir. Más bien, conseguir contar la propia historia. Sin la menor duda posible, todos $y$ todas tenemos algo que narrar. ¿Qué relatos leo que se acercan a mí?, ¿con qué relatos del país o de la región me estoy identificando ahora? Además, ¿qué relatos estoy escribiendo que proyectan mi ser y con los que me identifico?, ¿qué relatos se están escribiendo ahora acerca del país o de la región, que a la larga contribuirán a configurar nuestra identidad latinoamericana?

En todo caso, narrar la propia historia es clave. Es fundamental. No hay más espacio para el silencio y la autocensura. De nuevo: todos tenemos algo que decir.

\subsection{Una joven mujer, una historia de vida}

Cristina Orellana es una joven de 23 años, originaria de Guarjila, Chalatenango, al norte de la capital, San Salvador, en El Salvador. Estudia cuarto año de la carrera de Comunicación Social en la Universidad Centroamericana José Simeón Cañas (UCA) gracias a una beca que consiguió en su comunidad y que gestionó el sacerdote jesuita Jon de Cortina, quien dedicó la mayor parte de su vida a las personas de esa zona del país que tuvieron 
que huir durante la guerra hacia Honduras, debido a las masacres perpetradas por el ejército nacional.

Al igual que otros jóvenes de su edad que se hallan becados en la universidad, Cristina estudió su educación preuniversitaria en un instituto público (los cuales en general imparten una educación de menor calidad que la de los colegios privados), vive solo con su mamá (su padre murió durante el conflicto armado) y luce como una persona que no es de la capital (lenguaje, vestuario, gestos, ademanes). Sin embargo, hay algo que la diferencia de la mayoría: su promedio general de $9.03 \mathrm{y}$, hasta la fecha, no ha dejado ninguna asignatura, todas las ha aprobado en primera matrícula. A varios otros becarios $-y$, claro, también a quienes no lo son- les ha costado mucho más el proceso: algunos abandonan de plano el intento después de un primer año académico colmado de frustraciones; otros obtienen bajos resultados en los dos primeros años, pero luego se estabilizan $y$, no sin ciertas dificultades, empiezan a salir adelante; y otros más se tardan entre 8 y 9 años para finalizar una carrera cuya duración es de 5 años.

¿Por qué a Cristina le ha ido distinto?, ¿en qué radica la diferencia? Contestar esa interrogante fue la intención de mi trabajo de posgrado de una maestría en Educación que cursé de manera semipresencial. Como es dable suponer, una pregunta así carece de una única respuesta sencilla. Mi tesis es que existen al menos seis factores que se correlacionan positivamente con el rendimiento académico de los becarios de la UCA, a saber: los hábitos de estudio, el capital cultural, el apoyo y la influencia de la familia, la resiliencia y los factores particulares de protección y de riesgo, la autoestima y el nivel de adaptación al ámbito urbano y al ambiente universitario. Quiero retomar en este parte del trabajo el cuarto de esos factores porque, me parece, guarda relación con el apartado anterior y con la temática que acá se aborda.

¿A qué se le llama resiliencia? A la capacidad del ser humano para hacerle frente a las adversidades e incertidumbres de la vida, superarlas y ser transformado positivamente por ellas. En español y en francés, el término de resiliencia se emplea en metalúrgica e ingeniería civil para describir la capacidad de algunos materiales de recobrar su forma original después de ser sometidos a una presión deformadora. De allí, el término es retomado por las ciencias sociales para caracterizar a aquellas personas que, a pesar de nacer y vivir en condiciones de alto riesgo, se desarrollan psicológicamente sanos y socialmente exitosos.

¿Qué es lo que hace resilientes a las personas? Sin duda existen factores internos: la autoestima, el optimismo, la fe, la confianza en sí mismo, la responsabilidad, la capacidad de elegir. Pero también existen dos aspectos complementarios: los factores de riesgo y los factores de protección. 
Los factores de riesgo son aquellas características, hechos o situaciones propias del niño/a o adolescente que aumentan la posibilidad de daño biológico, psicológico o social. Deben verse como resultado de la estrecha interacción individuo-ambiente. Como nadie es un receptor pasivo de los diferentes estímulos, se trata de modular o ajustar constantemente la incidencia que cada estímulo puede llegar a tener en nuestra conducta. ¿De qué manera se hace ese ajuste? Se combinan componentes genéticos, psicológicos, sociales y situacionales, más el carácter específico de cada persona. Es decir que los factores de riesgo tendrán una dinámica propia, única, en cada ser humano, y su influencia dependerá de cómo se articulan en el interior de cada persona los componentes referidos con anterioridad.

Los factores de protección son aquellas características, hechos o situaciones propias del niño/a o adolescente que elevan su capacidad para hacer frente a la adversidad o disminuyen la posibilidad de daño biológico, psicológico o social. Se consideran como "un algo" que opera para mitigar los efectos del riesgo, y como fuerzas internas $y$ externas que contribuyen a que la persona resista o aminore los efectos del riesgo. Al igual que los anteriores, los factores de protección involucran también variables genéticas, disposiciones personales (sentido de autonomía, habilidades comunicativas y de resolución de problemas, autoestima elevada, creatividad, sentido del humor, tolerancia a las frustraciones, entre otras), elementos psicológicos y familiares (presencia de apoyo incondicional de por al menos una persona emocionalmente estable, creencias religiosas que promuevan la unidad familiar y la búsqueda de significados en los tiempos difíciles) y aspectos sociales.

Como puede notarse, los factores de protección y de riesgo se relacionan con la resiliencia, sobre todo en dos sentidos: a) la resiliencia puede ser fomentada: tanto los factores temperamentales (que vienen con el nacimiento, pero pueden ser moldeados) como los ambientales pueden ser promovidos y modificados; cualquier persona puede promover la resiliencia en otra al brindar afecto, confianza básica e independencia; b) la resiliencia es una capacidad universal: toda persona posee el potencial de desarrollar y mostrar su resiliencia. Todo ser humano cuenta con ciertos recursos que lo pueden ayudar a sobrellevar la adversidad.

Así, se les llama personas resilientes o con personalidad resistente a quienes tienen la capacidad de utilizar aquellos factores de protección para sobreponerse a la dificultad y crecer y desarrollarse adecuadamente, pese a los pronósticos desfavorables.

¿Ha influido el grado de resiliencia de Cristina en su satisfactorio rendimiento académico? Como 
dije, es este uno de los factores positivamente asociado al hecho. Y creo que en el caso de esta estudiante, la correlación es más clara por lo siguiente:

1. Encontró en Jon de Cortina a alguien más que al sacerdote confesor: al amigo y a quien vino a reemplazar la figura del padre.

2. La mamá de Cristina ha sido y es un apoyo fundamental en su vida. Ella le ha inculcado, con su ejemplo personal, el compromiso por salir adelante. Compromiso que Cristina ve reflejado tanto en ella como en cada miembro de su comunidad de Guarjila que tuvo que huir de donde vivían, para luego salir adelante en condiciones de extrema pobreza en la frontera con Honduras y después regresar a repoblar la zona y reconstruir su vida e historia, colectiva y de cada persona.

3. Finalmente, el elemento que considero de mayor peso: Cristina se acostumbró desde pequeña a relatar su vida, a contar su historia al hacer propias las palabras para transformar el mundo, su mundo. A los 12 años, formó parte de una radioemisora de la comunidad. Fue conductora de un programa infantil que sirvió, entre otros, a estrechar los lazos de amistad con Jon de Cortina. Luego, optó por Comunicación Social y por requisitos propios de esa carrera universitaria empezó a escribir relatos de su historia personal como parte de las tareas de asignaturas del tipo Redacción I, Redacción II (en ambas tuve la oportunidad de ser su profesor), Comunicación Aplicada, Semiótica de la Cultura, entre otras.

El segundo ciclo académico de 2008, Cristina cursó conmigo una materia más: Periodismo y Narración. El objetivo de la asignatura es apreciar cómo ciertos textos periodísticos echan mano de la técnica descriptiva y la técnica narrativa para comunicar mejor lo que desean expresar. Lo anterior se lleva a cabo de dos maneras: por un lado, lectura y análisis de abundantes textos periodísticos (crónicas, reportajes, entrevistas de perfil) en los que se aprecia la incorporación de esas técnicas $y$, por otra parte, elaboración de textos (periodísticos pero también personales) en que los y las estudiantes apliquen esos conocimientos a través de la incorporación de elementos descriptivos y narrativos.

Cristina entregó como tarea una crónica acerca de cómo Guarjila recibió la noticia del accidente del padre Jon, cómo se organizaron en la comunidad para orar por su salud $y$, finalmente, la profunda tristeza y desolación que sintieron cada una de las personas al saber que Jon había fallecido y que no podría acompañarlas más.

Hace un par de días les envió un correo electrónico a sus amistades en el que les adjunta su crónica. Gracias a que incorporó mi dirección entre sus destinatarios, puedo compartir acá el texto de ese correo. 
¡Hola amigos y amigas!

Me había perdido por unos días, pero todavía estoy viva. Sigo, como siempre, echándole muchas ganas a mis estudios en la universidad. Este es mi cuarto año de Comunicación Social y estoy por finalizarlo. Durante los próximos días tengo parciales finales. Un poco cansado, pero interesante todo lo que tengo que hacer. Ya veré cómo salgo con todo.

Hoy quiero compartir con ustedes una crónica que escribí hace poco en una materia que se llama Periodismo y Narración. Esa materia es lo mejor que puede existir, no se imaginan cuánto la disfrutamos y aprendemos cada día. Y más cuando nos encanta ese mundo, en donde podemos jugar con las letras y convertirlas en nuestras mejores aliadas para poder expresar lo que se siente, se piensa y se observa. Es muy bonita la materia y la manera de aprender.

Bueno, aquí se las envío. Es una crónica que escribí para el Padre Jon cuando la gente de Guarjila y yo me enteré que tuvo el derrame cerebral en Guatemala y la noticia cuando él murió. Es un poco triste, pero cada letra, cada línea que escribí lo hice pensando en él. Esas páginas están llenas de muchos sentimientos encontrados, lágrimas y dolor, pero asimismo están repletas de todo el amor y el cariño que le tenemos. Fue difícil para mí escribir sobre este tema, pero acá la tienen.

Freire de nuevo: "Existir, humanamente, es pronunciar el mundo, es transformarlo. El mundo pronunciado, a su vez, retorna problematizado a los sujetos pronunciantes, exigiendo de ellos un nuevo pronunciamiento. Los hombres no se hacen en el silencio sino en la palabra, en el trabajo, en la acción, en la reflexión. Mas si decir palabra verdadera, que es trabajo, que es praxis, es transformar el mundo, decirla no es privilegio de algunos hombres (Freire, 1970).

\subsection{Ciudadanía y narración}

Finalmente, de todo esto también puede resultar una lectura reflexiva y a la vez crítica acerca del derecho a la comunicación y a la identidad narrativa que como personas tenemos. Según se lee en la introducción del libro Ya no es posible el silencio, la fórmula de la comunicación ciudadana es: + ciudadanía + narración + activismo.

Así, entre otros aspectos, se plantea que como ciudadanos y ciudadanas tenemos derecho a demandar expresión, pues tenemos necesidad de hacer visibles nuestros relatos. Además, "demanda de identidad: necesidad de encontrar un lugar narrativo, estético y político para lo que uno es y lo que produce y lo que imagina. Responder a estas de- 
mandas debería de ser la condición de toda comunicación ciudadana para así 'comprender' expresivamente a las nuevas subjetividades, las nuevas sensibilidades, las viejas oralidades, las otras identidades... y así vincular al ciudadano en una acción más política y menos individualista (...) Todos somos hijos de la comunicación, luego sabemos narrar y queremos producir comunicación" (Centro de Competencia de Comunicación para América Latina, 2007).

Se trata de practicar el activismo comunicativo a través de nuevas vivencias de comunicación que conduzcan a que la gente produzca sus propios mensajes como estrategia de resistencia o resiliencia estética, comunicativa y política.

En plena consonancia con nuestros dos autores estudiados, el texto plantea que los medios ciudadanos deben comprometerse a contar historias que generen identificación. ¿Cómo?: "Contar a la gente y sus vidas, convertirlas en personajes, intentar que cada ciudadano sea un productor de mensajes, un rostro posible, una historia viable. El tono del humor es necesario para que la comunicación nos haga sonreír, pero con inteligencia, pues se genera identificación cultural desde lo irónico, lo sarcástico, la irreverencia" (Centro de Competencia de Comunicación para América Latina, 2007).

También se coincide acá con que no es necesario que la persona escriba una novela, cuento, poema u otra forma muy elaborada de narración, porque "el fragmento es el modo de narrar porque así es la vida, Ilena de diversidad temporal, flujo de momentos aburridos con experiencias sublimes, intentos de sentido con ganancias afectivas".

Se trata de contar esos sonidos, esos detalles, esas marcas cotidianas del relato que constituyen nuestros territorios y culturas para generar identificación y profundidad al relato. Debemos buscar las formas estéticas, narrativas, temporales y de ritmo que vienen inscritas en cada región, en cada nación indígena, en cada propuesta femenina, en cada identidad afro, en cada nueva sexualidad. Esas estéticas y éticas y políticas y narraciones todavía no han encontrado la forma mediática. La posibilidad es la comunicación.

\section{Palabras finales. A manera de conclusión}

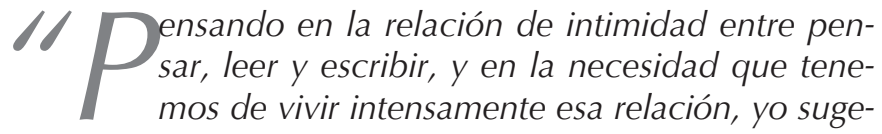

riría a quien pretenda experimentarla rigurosamente que se entregue a la tarea de escribir algo por lo menos tres veces por semana. Una nota sobre una lectura, un comentario sobre algún suceso del cual tomó conocimiento por la prensa, 
por la televisión, no importa. Una carta para un destinatario inexistente" (Freire, Cartas a quien pretende enseñar).

La identidad concebida como lo mismo (ídem) se sustituye por una identidad concebida como símismo (ipse). Esta última identidad es conforme a la estructura temporal dinámica que surge de la composición propia del relato. Por eso, el sujeto de la acción aparece como el lector y el escritor de su propia vida. El agente actúa en el mundo y en el seno de un contexto dado, pero al mismo tiempo, el sentido de su acción sólo le es accesible a través de la lectura de su historia. Es posible ver aquí el aspecto circular de esta comprensión: en el mismo acto que me comprendo a mí mismo a través de la narración, me construyo. De ese modo, la mediación narrativa permite, a su vez, que sea posible rescribir a lo largo de la vida diferentes tramas de mi existencia.

Nos construimos sobre narraciones, somos a partir de los relatos. Ello es lo que asegura nuestra identidad a lo largo de lo cambiante de nuestras vidas. La comprensión de nosotros, de nuestros pueblos, de la gente está así mediatizada por los textos en los que nos relatamos. En ello se descubre lo plural, lo diferente, lo otro que nos conforma. De esta manera, la identidad narrativa nos abre un mundo que nos posibilita comprendernos a nosotros mismos en nuestra pluralidad, lo que le hace un elemento muy importante para la construcción de nuestra co- lectividad. Responder a la pregunta ¿quién? es narrar la historia de una vida.

Como bien afirma el maestro Jesús Martín Babero, comunicador colombiano: "La relación entre expresividad y reconocimiento de la identidad se hace precisamente visible en la polisemia castellana del verbo contar cuando nos referimos a los derechos de las culturas, tanto de las minorías como de los pueblos, pues para que la pluralidad de las culturas del mundo sea políticamente tenida en cuenta, es indispensable que la diversidad de identidades pueda ser contada, narrada. La relación de la narración con la identidad es constitutiva: no hay identidad cultural que no sea contada. Ahí apunta la nueva comprensión de la identidad como una construcción que se relata. $Y$ lo hace en cada uno de los idiomas y al mismo tiempo en el lenguaje multimedial en el que hoy se juega el movimiento de las traducciones, de lo oral a lo escrito, a lo audiovisual, a lo informático" (Martín Barbero, 2001).

En julio de 1992, Paulo Freire visitó El Salvador. Hacía 6 meses se habían firmado los Acuerdos de Paz que lograron finalizar con doce años de guerra civil. Docentes de la Universidad de El Salvador (UES) -en donde le otorgaron el doctorado honoris causa- y campesinos 
y campesinas que lucharon durante años con armas en las manos y que habían aprendido a leer y a escribir las palabras lo invitaron para mostrarle lo que habían hecho y lo que estaban haciendo.

A las reflexiones que se suscitaron en él a partir de esta visita, Freire le dedica las últimas 6 páginas de su Pedagogía de la esperanza. Entre otras palabras, el educador brasileño señala: "Una vez más la Pedagogía del oprimido estuvo en el centro del debate, con sus tesis fundamentales más actuales y más vivas que en los años setenta. Ella, y no solamente los trabajos de alfabetización para adultos realizados en los campamentos guerrilleros. Tal vez diría mejor que la Pedagogía del oprimido estuvo presente como arma fundamental de la alfabetización realizada como lectura del mundo y como lectura de la palabra, como lectura del contexto y lectura del texto, como práctica y teoría en una unidad dialéctica" (Freire, 1993).

Asimismo, cuenta Freire que durante su estancia en El Salvador visitó diferentes regiones del país y que estuvo "en una linda área abierta en el monte, una especie de escenario donde los guerrilleros se reunían y se reúnen para discutir, para soñar, para evaluarse y para divertirse (...) Desde la cima de una elevación veíamos todo un mundo por construir de un modo diferente". La zona en cuestión queda en el departamento de Morazán y se llama Segundo Montes, el nombre de uno de los jesuitas asesinados por la Fuerza Armada durante la ofensiva guerrillera de noviembre de 1989. Las personas de esta comunidad, al igual que Cristina Orellana y su madre en el norte de Chalatenango, tuvieron que refugiarse varios años en Honduras huyendo de las matanzas de mujeres, niños y hombres que hacía el ejército nacional.

Allí, en Segundo Montes, relata Freire (1993), "presenciamos una sesión de un Círculo de Cultura en que los militantes armados se alfabetizaban, aprendían a leer palabras haciendo la relectura del mundo. EI aprendizaje de la escritura y de la lectura de la palabra, que hacían en la comprensión del discurso, emergía o formaba parte de un proceso mayor y más significativo: el de asumir su ciudadanía, el de tomar la historia en las manos. Es esto lo que siempre he defendido y es por esto por lo que siempre me he batido por una alfabetización que conociendo la naturaleza social de la adquisición del lenguaje jamás la separe del proceso político de la lucha por la ciudadanía".

Al leer esas palabras de Freire, es inevitable preguntarse qué pasó con aquellos ideales por los que se luchó y murió tanta gente y dónde quedó esa asunción de ciudadanía y ese tomar la historia en las manos. Y sin embargo, con suma claridad, de inmediato me viene a la mente una frase, que no intenta responder ninguna de esas preguntas, sino simplemente expresar: todavía es 
posible, pero hay mucho por hacer. Una tarea concreta que está en mis manos llevar a cabo, y que terminará por constituirse en un punto de partida, es la de animar y motivar a mis estudiantes a escribir su propia historia de vida a través de múltiples relatos y desde múltiples lenguajes: escrito, radiofónico, audiovisual, haciendo uso también de las nuevas tecnologías. Creo en la fuerza del poder de la palabra.

Así concluye Freire sus reflexiones de su visita a este país: "Las más duras dificultades del pueblo,

\section{Referencias}

- Centro de Competencia en Comunicación para América Latina (2007). Ya no es posible el silencio. Friedrich Ebert Stiftung: Colombia.

- Díaz Genis, A. (2004). La construcción de la identidad en América Latina. Editorial Nordan: Uruguay.

- Freire, P. (1970). Pedagogía del oprimido. Siglo Veintiuno Editores: Argentina.

- Freire, P. (1993). Pedagogía de la esperanza. Siglo Veintiuno Editores: Argentina.

- Freire, P. (1994). Cartas a quien pretende enseñar. Siglo Veintiuno Editores: Argentina. las idas y venidas del proceso que dependen de muchos factores para solidificarse, nada de eso ha disminuido, en Nita ${ }^{5}$ y en mí mismo, la esperanza con que llegamos a El Salvador, con que vivimos en El Salvador y con que dejamos El Salvador. La misma esperanza con la que termino esta Pedagogía de la esperanza".

La identidad latinoamericana es un proceso en construcción. Somos siendo. No podemos quedarnos con los brazos cruzados.

- Freire, P. (1996). Cartas a Cristina. Reflexiones sobre mi vida y mi trabajo. Siglo Veintiuno Editores: Argentina.

Martín Barbero, J. (2001), en Vasallo de López, María Immacolata y Fuentes Navaro, Raúl. Comunicación: campo y objetivo de estudio. Guadalajara: Iteso.

- Mouffe, C. (2003). La paradoja democrática. Editorial Gedisa S. A., primera edición. Barcelona: España.

- Ricoeur, P. (1996) Sí mismo como otro. Siglo Veintiuno Editores: España.

- Ricoeur, P. (1999) Historia y narratividad. Ediciones Paidós Ibérica: España. 
Notas

1 Según el Diccionario de la Real Academia Española (DRAE, 2007), “poyo de fábrica o armazón de madera que sirve para poner los cántaros”. Un cántaro, según el mismo diccionario, es "una vasija grande, de barro o metal, angosta de boca, ancha por la barriga y estrecha por el pie y por lo común con una o dos asas”. Sirve para colocar o transportar agua.

2 De allí que Freire afirme, tajante: "El monólogo, en cuanto aislamiento, es la negación del hombre. Es el cierre de la conciencia, mientras que la conciencia es apertura” (Óp. cit., p. 13).

3 Ciertamente no pretendo comprender a cabalidad el pensamiento tan complejo y sugerente de este autor francés, a quien apenas he empezado a leer. Profundizar en sus planteamientos $-\mathrm{y}$ en todo lo que tenga que ver con Gadamer y la hermenéuticaes una tarea pendiente.

$4 \quad$ Se refiere al Cogito de Descartes y al anti-Cogito de Nietzsche.

$5 \quad$ Se refiere a su segunda esposa. 